\title{
Which Emotional Intelligence? A Comparison of Measures and Implications for Counseling Psychology
}

\author{
John Pellitteri, Nina Lei \\ Queens College, City University of New York, New York, USA
}

\begin{abstract}
The increased application of Emotional Intelligence (EI) in psychology warrants clarification of conceptualization and measurement approaches. Two predominant measures of EI, the Mayer, Salovey, and Caruso Emotional Intelligence Test (MSCEIT) and the Bar-On Emotional Quotient Inventory (EQi), were compared with bivariate and factor analysis techniques. The absence of common factor structures, pattern of low subtest correlations, and distinct relations to cognitive reasoning suggest that the instruments measure significantly different constructs. It would be erroneous to assume that EI is one unified concept. Implications are that counseling psychologists be aware of the distinct models of EI in order to coordinate effective assessment and interventions.
\end{abstract}

Keywords: emotional intelligence, positive psychology, assessment, MSCEIT, EQi

The construct of emotional intelligence (EI) provides a framework of emotional functioning that can guide clinical and educational interventions for counseling psychologists. Emerging from the perspective of multiple intelligence (Gardner, 1983), EI is considered to be a type of intelligence that is distinct from IQ and predictive of personal-social adjustment and well-being (Bar-On, 1996; Mayer \& Salovey, 1997; Salovey \& Mayer, 1990). Counseling psychology, with its emphasis on psychoeducation, prevention, and optimal development, can readily embrace the tenets of EI and has historically focused on related aspects of social-emotional functioning (Gelso, Nutt-Williams, \& Fretz, 2014). The identification of individual social-emotional strengths and the capacities to generate positive emotions are closely aligned with the principles of positive psychology (Magyar-Moe, Owens, \& Conoley, 2015). The importance of applying strength-based assessment methods to infuse positive psychology into counseling psychology has been noted (Magyar-Moe, Owens, \& Scheel, 2015) and warrants a closer examination of EI measures.

There is growing interest in EI as it applies to various areas of counseling such as education (Brackett, Rivers, Reyes, \& Salovey, 2012; Graczyk, Weissberg, Payton, Elias, Greenberg, \& Zins, 2000), child development (Payton, Wardlaw, Graczyk, Bloodworth, Tompsett, \& Weissberg, 2000; Salovey \& Sluyter, 1997), psychotherapy (Kaplowitz, Safran, \& Muran, 2011; Nyklicek, Schalken, \& Meertens, 2014; Parker, 2000; Rieck \& Callahan, 2013), parenting (Alegre, 2012; Aminabadi, Pourkazemi, Babapour, \& Oskouei, 2012; Elias, Tobias, \& Friedlander, 1999), and career/workplace settings (Cherniss, 2000; De Clercq, Bouckenooghe, Raja, \& Matsyborska, 2014; Goleman, 1998; Greenidge \& Coyne, 2014; Schutte \& Loi, 2014; Wan, Downey,

John Pellitteri, Graduate Program in Counseling, Department of Educational \& Community Programs, Queens College, City University of New York.

Nina Lei, Graduate Program in Counseling, Department of Educational \& Community Programs, Queens College, City University of New York. 
\& Stough, 2014). Such widespread applications attest to the necessity for valid measurement instruments to evaluate clinical needs and assess the impact of interventions. It is essential that psychologists have an understanding of the existing EI measures and their underlying conceptualizations in order to incorporate EI into their work. Counselors need to make appropriate choices of instruments relevant to their client populations in educational, mental health, and career settings and target areas of intervention that are consistent with the measures.

Some of the challenges in measuring and applying EI lie in its definition. Controversy exists in the field as to the place of EI as a personality trait or set of mental abilities (Matthews, Zeidner, \& Roberts, 2004; Mayer, 2008; Mayer, Salovey, \& Caruso, 2000a; Petrides, 2011). As different tests purport to measure EI and yet rest on different conceptual descriptions, definition and measurement becomes inextricably intertwined. The evolution of the field of general intelligence (i.e., IQ) over the last century shows a diversity of conceptualizations and measurement challenges (Sternberg, 1990). In the parallel field of EI, caution must be exercised so as to avoid the pitfall of the adage that was once used to define IQ: (Emotional) intelligence is "what the test tests!” (Boring, 1923, p. 35).

The two most prominent instruments that have emerged in EI research are the Mayer, Salovey, and Caruso Emotional Intelligence Test (MSCEIT) (Multi-Health Systems, 1999) and the Bar-On Emotional Quotient Inventory (EQi) (Multi-Health Systems, 1997). These tests are not only the most developed tools in the field, but also represent two distinct approaches to measurement. The structure of the MSCEIT is based on task-oriented skills such as identifying emotions in pictures, describing emotions, and social reasoning based on emotions. It is a second generation instrument that evolved from an earlier abilities measure- the Multifactoral Emotional Intelligence Scales (MEIS) (Mayer et al., 1999; 2000). The EQi is a self-report Likert scale measure that describes traits and potential for emotionally intelligent behavior and is based on several international samples.

Important considerations in the comparison of these measures are the different formats (abilities measure versus self-report) and the conceptual definitions of EI upon which the tests are based. One would expect that if the tests are measuring the same construct, then convergent validity would emerge through a correspondence between their factor structures and overall results. Normative research with each test has reported correlations between the total scores of the respective measures (Bar-On, 2000; Mayer, Salovey, \& Caruso, 1999) but has not explored the underlying factor structures. An understanding of common factors between measures is important. Once central aspects are understood, then core components of the EI construct can be more clearly defined and its implications for counseling can be more readily applied.

The first formal definition of EI was provided by Salovey and Mayer (1990) and has been refined over the years to become the basis of their current abilities-based instrument. Their current definition is:

The ability to perceive accurately, appraise and express emotion; the ability to access and/or generate feelings when they facilitate thought; the ability to understand emotion and emotional knowledge; and the ability to regulate emotions to promote emotional and intellectual growth. (Mayer \& Salovey, 1997, p. 10)

Working independently, Bar-On (1997) developed a construct of EI that is comprised of 15 personality factor components. Bar-On defines EI as: "an array of personal, emotional, and social competencies and skills that influence one's ability to succeed in coping with environmental demands and pressures” (p. 3). Bar-On emphasizes that his model relates to the "potential for performance, rather than performance itself (i.e., the potential to succeed rather than success itself)” (p. 3). 
An understanding of the commonalities and distinctions between the MSCEIT and EQi is important for psychologists to better determine the relevance and fit of the respective measures to areas of professional practice. This study will explore three major questions: (1) Are there common factors between the MSCEIT and the EQi that might represent core EI elements? (2) Which components and structures of the MSCEIT and EQi are related to each other? and (3) What are the relationships of the MSCEIT and EQi to general intelligence?

\section{Method}

\section{Participants}

The sample consisted of 130 adults enrolled in college in an East Coast urban setting and included 80 females (61\%) and 50 males (39\%) with an average age of 24 years. The self-identified ethnic breakdown of the sample included Caucasian (41\%), Asian (20\%), Hispanic (14\%), African-American (3\%), and Mixed Race/Other (22\%). The participants received credit toward an introductory psychology course for participation in the study.

\section{Measures}

Mayer, Salovey, and Caruso Emotional Intelligence Test. The ability-based test designed by Mayer et al. (1999) is comprised of 12 subtests that cluster together to form four branches. The test requires participants to perform several tasks that relate directly to the four components of the Mayer and Salovey (1997) definition of emotional intelligence.

The first branch, "Emotional Perception”, is comprised of tasks that use a 5-point Likert scale requiring subjects to identify the degree that emotions are present in pictures of human faces, landscapes, and abstract designs. The second branch, "Emotional Integration", is comprised of tasks that use a 5-point Likert scale to compare emotions to various sensory modalities (Synesthesia and Sensation Translation) and the "helpfulness" of emotions in influencing thinking (Facilitation). The tasks of the third branch, "Emotional Understanding", utilize a 5-answer multiple choice format to assess the subjects' knowledge of the combinations of simpler affects within complex emotions (Blends), the change in the intensity of emotions over time (Progressions and Transitions), and the conceptual relations of emotions (Analogies). The tasks of the fourth branch, "Emotional Management”, require subjects read short vignettes and use a 5-point Likert scale format to rate the effectiveness of actions in managing the emotions of the characters in the stories (Emotion Management) and influencing others in interpersonal situations (Emotions in Relationships).

The reliability of the MSCEIT is high. The alpha coefficients range from: Branch $2=0.77$; Branch $1=$ 0.87; Branch $3=0.90$; Branch $4=0.91$; and the Full Test Score $=0.92$. Structural validity was established with factor analytic methods where the subtests loaded on the four respective branches. The loadings for Branch 1 ranged from 0.50 to 0.99; for Branch 2, they ranged from 0.62 to 0.76; for Branch 3 from 0.55 to 0.83; and for Branch 4 from 0.49 to 0.78 (Mayer et al., 1999).

Emotional Quotient Inventory. The EQi (Bar-On, 1997) is a 133-item self-report measure that uses a 5-point Likert scale format where participants rate the degree to which brief statements are "True of Me" to "Not True of Me”. Examples of such statements are: "It's fairly easy for me to express feelings", "I feel sure of myself in most situations", and "I'm sensitive to the feelings of others". The measure yields a total EQ score, five component scores, 15 subscale scores, and four validity scores. 
The EQi has been extensively researched and is based on three samples in North America (combined $N=$ 6,396); and several smaller samples in Argentina $(N=446)$, Germany $(N=168)$, South Africa $(N=448)$, Nigeria $(N=267)$, Israel $(N=418)$, and India $(N=235)$. Cronbach alphas for the subtests across all samples range from 0.59 to 0.90 , with many above 0.70 and 0.80 . Test-retest reliabilities across the samples range from 0.79 to 0.92 at one month and 0.55 to 0.80 at four months. Structural validity for the EQi is established by factor analysis methods that support a five factor solution corresponding to the five component structure of the test. Convergent and divergent validity is based on correlations in expected directions with various measures of personality (Bar-On, 1997).

16PF B-scale. The B-Scale of the Sixteen Personality Factor Questionnaire is a 15-item multiple choice test that consists of verbal and numerical reasoning tasks. It was validated separately from the other scales of the $16 \mathrm{PF}$ and is used independently as a measure of general intelligence/cognitive reasoning. The test-retest reliability was 0.69 and 0.65 after two weeks and two months, respectively, and the Cronbach alpha coefficient was 0.77 . Validation was established through positive correlations with other measures of intelligence, such as the Information Inventory (0.61) and the Culture Fair Intelligence Test (0.51) (Russell \& Karol, 1994).

\section{Procedures and Data Analysis}

Each participant completed a demographic questionnaire and then completed the MSCEIT, EQi, and 16PF-B scale in alternating order working independently in small groups. The statistical analyses consisted of two levels of bivariate correlations, first with the total scores, componential scores, and 16PF score, and then with the 27 subtests that comprised the components (12 for the MCSEIT and 15 for the EQi). Factor analysis was used to examine common factors between the subtest variables of the two measures.

\section{Results}

Bivariate correlations of the total and component scores for the MSCEIT and EQi are presented in Table 1. Review of the inter-test correlations were statistically significant ranging from 0.15 to 0.19 . The MSCEIT total score correlated with the EQi Interpersonal component $(r=0.15, p<0.05)$. The MSCEIT Branch 1 (Emotional Perception) correlated with the Total EQi score $(r=0.16, p<0.05)$, the EQi Intrapersonal component $(r=0.16$, $p<0.05$ ), and the EQi Adaptation component $(r=0.19, p<0.05$ ). The MSCEIT Branch 3 (Understanding Emotions) correlated with the EQi Interpersonal component $(r=0.17, p<0.05)$. The MCSEIT Branch 4 (Managing Emotions) correlated to the Total EQi score $(r=0.17, p<0.05)$ and the EQi Interpersonal component $(r=0.19, p<0.05)$. One component from each test, the MSCEIT Branch 1 (Emotional Perception) and the EQi Interpersonal component, while not correlated to each other, had significant correlations with the total score and two componential scores of the other test. These two components comprised six of the seven significant inter-test correlations in the analysis.

Intra-test correlations were as expected with the four MSCEIT branches correlating significantly with the MSCEIT total score at the $p<0.01$ level and ranging from 0.75 to 0.84 . The correlations between the MSCEIT branches ranged from 0.36 to 0.69 also at the $p<0.01$ level. Similarly, the intra-test correlations between the EQi components and the EQi Total were significant at the $p<0.01$ level and ranged from 0.64 to 0.88 . Correlations between the EQi components were significant at the $p<0.01$ level and ranged from 0.23 to 0.67.

The third measure in the study, the 16PF B-Scale, which measures cognitive reasoning, had a moderate correlation with the MSCEIT Total score $(r=0.35, p<0.01)$. The 16PF B-Scale correlated respectively with 
the MSCEIT Branch 2 ( $r=0.25, p<0.01)$, Branch $3(r=0.45, p<0.01)$, and Branch $4(r=0.30, p<0.01)$. The 16PF B-Scale was uncorrelated with the EQi and its components.

Table 1

Bivariate Correlations Between the Total and Component Scores of the MSCEIT and EQi

\begin{tabular}{|c|c|c|c|c|c|c|c|c|c|c|c|c|}
\hline & (1) & $(2)$ & (3) & (4) & (5) & (6) & (7) & $(8)$ & (9) & $(10)$ & (11) & $(12)$ \\
\hline (1) MCSEIT Total & --- & & & & & & & & & & & \\
\hline (2) MSCEIT Perception ( I) & $0.75^{* *}$ & --- & & & & & & & & & & \\
\hline (3) MSCEIT Integration (II) & $0.82^{* *}$ & $0.53^{* *}$ & --- & & & & & & & & & \\
\hline (4) MSCEIT Understanding (III) & $0.84^{* *}$ & $0.41^{* *}$ & $0.55^{* *}$ & --- & & & & & & & & \\
\hline (5) MSCEIT Management (IV) & $0.77^{* *}$ & $0.36^{* *}$ & $0.60^{* *}$ & $0.69^{* *}$ & --- & & & & & & & \\
\hline (6)EQi Total & 0.13 & $0.16^{*}$ & 0.11 & 0.07 & $0.17^{*}$ & --- & & & & & & \\
\hline (7) EQi Intrapersonal & 0.10 & $0.16^{*}$ & 0.12 & -0.01 & 0.14 & $0.88^{* *}$ & --- & & & & & \\
\hline (8) EQi Interpersonal & $0.15^{*}$ & 0.11 & 0.08 & $0.17^{*}$ & $0.19^{*}$ & $0.64^{* *}$ & $0.40^{* *}$ & --- & & & & \\
\hline (9) EQi Adaptability & 0.13 & $0.19^{*}$ & 0.06 & 0.09 & 0.10 & $0.86^{* *}$ & $0.67^{* *}$ & $0.44^{* *}$ & --- & & & \\
\hline (10) EQi Stress Management & 0.06 & 0.03 & 0.07 & 0.03 & 0.13 & $0.65^{* *}$ & $0.44^{* *}$ & $0.23^{* *}$ & $0.63^{* *}$ & --- & & \\
\hline (11) EQi General Mood & 0.03 & 0.01 & 0.03 & 0.09 & 0.12 & $0.74^{* *}$ & $0.64^{* *}$ & $0.46^{* *}$ & $0.56^{* *}$ & $0.37^{* *}$ & --- & \\
\hline (12) Cognitive Reasoning & $0.35^{* *}$ & 0.12 & $0.25^{* *}$ & $0.45^{* *}$ & $0.30^{* *}$ & 0.04 & 0.01 & 0.09 & 0.04 & 0.08 & 0.06 & -- \\
\hline
\end{tabular}

Note. Significant inter-test correlations are listed in bold print. ${ }^{*}<0.05 ;{ }^{* *}<0.01$, one-tailed.

Table 2

Significant Bivariate Correlations $(p<0$.05) Between the Subtests of the MSCEIT and the EQi

\begin{tabular}{lll}
\hline EQi subtest (\& component) & Pearson correlation & MSCEIT subtest (\& branch) \\
\hline Emotional self-awareness (1) & 0.22 & Emotions in relations (I) \\
\hline Self-actualization (1) & 0.19 & Designs (I) \\
& 0.19 & Landscapes (I) \\
& 0.22 & Sensation translation (II) \\
& 0.21 & Blends (III) \\
Independence (1) & 0.24 & Emotional management (IV) \\
& 0.17 & Designs (I) \\
\hline Empathy (2) & 0.22 & Landscapes (I) \\
\hline Interpersonal relations (2) & 0.23 & Facilitation (II) \\
\hline & 0.20 & Emotional management (IV) \\
& 0.18 & Blends (III) \\
& 0.19 & Designs (I) \\
Reality testing (3) & 0.23 & Landscapes (I) \\
& 0.18 & Synesthesia (II) \\
& 0.20 & Sensation translation (II) \\
& 0.21 & Blends (III) \\
& 0.19 & Progressions (III) \\
& 0.19 & Emotions in relations (IV) \\
& 0.19 & Emotional management (IV)
\end{tabular}

Note. The corresponding component for each EQi subtest and the corresponding branch for each MSCEIT subtest are noted in parentheses.

The next level of bivariate analysis examined the correlations between the 27 subtests that comprised the MSCEIT branches and the EQi components. The significant inter-test bivariate correlations of the 12 MSCEIT subtests and the 15 EQi subtests are presented in Table 2. The values range from 0.17 to 0.24 . Of the six EQi 
subtests that had significant correlations with the MSCEIT subtests, three (Emotional Self-awareness, Self Actualization, and Independence) were part of the EQi Intrapersonal component, two (Empathy and Interpersonal relationships) were part of the EQi Interpersonal component, and one (Reality Testing) was part of the EQi Adaptability component. The EQi Self Actualization subtests correlated with five of the MSCEIT subtests, which represented at least one from each of the four structural branches of the MSCEIT. The EQi Reality testing subtest correlated with the same five MSCEIT subtests as well as with three more.

Table 3

Factor Loadings for 7 Factor Rotated Solution

\begin{tabular}{|c|c|c|c|c|c|c|c|c|}
\hline \multirow{2}{*}{ Components } & \multirow{2}{*}{ Subtests } & \multicolumn{7}{|c|}{ Factors } \\
\hline & & $\mathrm{I}$ & II & III & IV & $\mathrm{V}$ & VI & VII \\
\hline \multicolumn{9}{|l|}{ EQi } \\
\hline \multirow{5}{*}{ Intrapersonal } & Emotional self-awareness & 0.51 & & & & & & \\
\hline & Assertiveness & 0.54 & & & & & -0.58 & \\
\hline & Self-Regard & 0.72 & & & & & & \\
\hline & Independence & 0.76 & & & & & & \\
\hline & Self-Actualization & 0.69 & & & & & & \\
\hline \multirow{3}{*}{ Interpersonal } & Empathy & & & & 0.87 & & & \\
\hline & Social Responsibility & & & & 0.77 & & & \\
\hline & Interpersonal Relationship & & & & 0.60 & & & \\
\hline \multirow{3}{*}{ Adaptability } & Reality Testing & 0.73 & & & & & & \\
\hline & Flexibility & & & & & -0.70 & & \\
\hline & Problem Solving & 0.49 & & & 0.48 & & & \\
\hline \multirow{2}{*}{ Stress management } & Impulse Control & & & & & & 0.80 & \\
\hline & Stress Tolerance & 0.82 & & & & & & \\
\hline \multirow{2}{*}{ General mood } & Optimism & 0.81 & & & & & & \\
\hline & Happiness & 0.44 & & & & 0.73 & & \\
\hline \multicolumn{9}{|l|}{ MSCEIT } \\
\hline \multirow{3}{*}{ Emotional perception } & Faces & & & 0.78 & & & & \\
\hline & Landscapes & & & 0.84 & & & & \\
\hline & Designs & & 0.41 & 0.75 & & & & \\
\hline \multirow{3}{*}{ Emotional integration } & Synesthesia & & 0.70 & & & & & \\
\hline & Sensation Translation & & 0.68 & & & & & \\
\hline & Facilitation & & 0.63 & & & & & -0.47 \\
\hline \multirow{4}{*}{ Emotional understanding } & Blends & & 0.61 & & & & & 0.44 \\
\hline & Progressions & & 0.62 & & & & & \\
\hline & Transitions & & 0.70 & & & & & \\
\hline & Analogies & & 0.46 & & & & & 0.55 \\
\hline \multirow{2}{*}{ Emotional management } & Emotion Management & & 0.79 & & & & & \\
\hline & Emotions in Relationships & & 0.79 & & & & & \\
\hline
\end{tabular}

Extraction Method: Principal Component Analysis; Rotation Method: Quartimax.

Note. Only loadings with coefficients of 0.40 or greater are shown.

The factor analysis principal component extraction produced seven factors with an Eigenvalue $>1.0$ that explained $65 \%$ of the variance. Table 3 presents the loadings for the rotated Quartimax factor solution. This orthogonal rotation method was chosen based on the assumption of a general factor. An oblique rotation was also performed since it was expected that the factors would be correlated. The loadings and factors structure of 
the oblique rotation did not differ significantly from the orthogonal rotation. In addition, the factor covariance matrix indicated that the factors were not highly correlated. Therefore only the orthogonal rotation is reported.

All of the factors loaded with subtests from only one of the two measures. There were no factors that contained subtests from both tests. Analysis of the factor covariance matrix indicates that the extracted factors were not correlated with each other. The first factor which accounts for $21 \%$ of the variance loaded with 10 of the 15 EQi subtests. The second factor accounted for $17 \%$ of the variance and included 10 of the 12 MSCEIT subtests. Factors 1 (General EQi) and 2 (General MSCEIT) can be labeled as such, since they appear to represent the separate "general" factors of the respective tests. Factors 3 and 4 represent identified components of each test that did not completely load onto the first two factors. Factor 3 (Interpersonal EQi) is comprised of the subtests of the EQi Interpersonal component and accounted for $7 \%$ of the variance. Factor 4 (Perception-MSCEIT) consists of the subtests of the MSCEIT Emotional Perception branch and accounts for 6\% of the variance.

Factors 5 and 6 each had only two EQi subtests with positive and negative loadings which makes interpretation questionable. Factor 5 consists of the Happiness subtest (0.73) and the flexibility subtests (-0.70) which might be viewed as a positive mood derived from rigidity. Factor 6 consists of the Impulse Control subtest (0.80) and Assertiveness (-0.58) which might be interpreted as a self-constrained passivity. Factor 7 had three MSCEIT subtests. Blends (0.44) and Analogies (0.55) are part of the Emotional Understanding branch and Facilitation (-0.47) is part of the Emotional Integration branch. Also of questionable meaning, this factor seems to represent a conceptual grasp of emotions without an integrated application of emotional information. Factor 5, 6, and 7 which respectively accounted for $5 \%, 5 \%$, and $4 \%$ of the variance, appear to indicate less adaptive patterns and in all likelihood are not significantly part of the test structures.

\section{Discussion}

\section{Comparative Analysis of Measures}

The structures of the MSCEIT and EQi are notably distinct given the non-significant correlations between the total scores, the pattern of non-significant and relatively low intercorrelations between the components/subtests, and the pattern of the respective subtests loading on separate and uncorrelated factors. Theoretical distinctions are further illustrated by their differences in relation to cognitive reasoning, with the abilities-based MSCEIT having moderate correlations with an IQ measure (16PF) and the trait-based EQi being uncorrelated. Normative studies by the respective test authors did report low to moderate correlations between total scores (Bar-On, 2000; Mayer et al., 1999). The findings in this current study further emphasize the assertion by Mayer et al. (1999) that the tests are "measuring substantially different constructs” (p. 33). This assertion is supported by results of other comparative studies (Livingstone \& Day, 2005; O'Conner \& Little, 2003). The disparity between models continues to illustrate what has been referred to as the "elusive" nature of the EI construct (Davies, Stankov, \& Roberts, 1998; Ybarra, Kross, \& Sanchez-Burks, 2014).

\section{Implications for Counseling Psychology}

The failure to identify common or central EI elements between the MSCEIT and EQi has important implications for counseling assessment and applications. Counseling psychologists choosing to use EI in their work need to decide "which EI" model (abilities versus traits) will be most applicable to their clinical population. There cannot be an assumption that EI is one unitary concept. The trait versus abilities distinction is 
important to avoid confusion since the term "EI" can represent each of these distinct definitions (as well as other blended EI models) and carry different implications for clinical practice. It is additionally necessary for counseling professionals to be knowledgeable about the varying perspectives since the use of the term EI in the public media has been at times exaggerated or misrepresented (Mayer et al., 2000a).

The type of data generated by the respective measures must be considered in the context of assessment purposes and targeted clinical outcomes. The abilities/trait distinction would be highly relevant, for example, if a psychologist wishes to use EI measures to assess the effectiveness of a psychoeducational program. If the EQi was used because of the ease of self-report format but the focus of the psychoeducational program was on teaching social-emotional abilities, then the EQi would not likely be sensitive to improvements. Evidence for the program's effectiveness therefore may not be accurately evaluated.

Beyond issues of measurement are the assumptions derived from each EI model and how these assumptions influence client conceptualization and counseling interventions. There are differences when working with a client's traits (which are assumed to be innate) and abilities (which can be learned and increased). This parallels approaches in education regarding individual's assumptions about their IQ, namely the "entity" versus "incremental" beliefs of abilities (Brophy, 2010). Trait-based models of EI are akin to entity theories where individuals believe that they possess a certain fixed amount of a capacity or characteristic. The abilities-based view of EI is aligned with an incremental theory and allows individuals to hold beliefs about increasing their own abilities. Incremental (i.e., ability) views have benefits for the client's self-efficacy and motivation, with the attribution that EI capacities can be improved. An entity (i.e., trait) perspective implies an acceptance of emotional "set points" and may suggest that EI cannot increase. Counseling psychologists therefore need to consider the implicit assumptions that come with adopting a particular EI orientation that addresses either emotion-based personality structures or an array of emotion-related abilities. Owens, Magyar-Moe and Lopez (2015) advise that clinicians, in positive psychology assessments, examine their constructions of implicit theories of client functioning.

The reciprocal influences between cognitive and emotional processes within a person are a central feature of the abilities-model and distinguish it from trait or blended EI models (Mayer et al., 2000b). Data generated by the MSCEIT will provide information about emotional abilities (such as recognizing emotions, facilitating thinking, and regulating feelings) that can influence social functioning. An individual's utilization of such abilities, however, will depend upon the specific process-oriented conditions of interpersonal relationships and social situations (i.e., a person may or may not use his or her ability to regulate emotions effectively in every situation). Thus when the focus of counseling is on an individual's intrapersonal and interpersonal "processes", then an EI abilities approach is more applicable. By contrast if the counseling focuses on an individual's "general tendencies" toward behaviors, thoughts, and attitudes in an environment, then trait EI data would be more fitting.

Traditional approaches to career counseling and work adjustment, for example, have been based on a trait and factor approach and the person-environment fit (Niles \& Harris-Bowlsbey, 2009). Data from the EQi is aligned with this approach as it creates a profile of a client's emotion-related traits and suggests a general tendency toward self-reported emotional-behavioral patterns. A person-environment fit approach to work adjustment would examine the match between these general tendencies in the person and the emotional characteristics of the work environment or co-workers. The EQi can provide an overall structure of the individual's emotional dimensions of personality and predict the general outcomes that may evolve from the 
degree of fit or misfit with the "personality" of the environment. Trait EI has been examined as an adaptive factor in organizations and the workplace (De Clercq et al., 2014; Greenidge \& Coyne, 2014; Schutte \& Loi, 2014; Wan et al., 2014). One can argue that a profile of EI abilities can also inform the person-environment fit, however, trait EI and the EQi tend to be utilized more often than ability EI in work and organizational settings.

Psychologists in clinical and mental health settings may be more likely to adopt the abilities-based model due to its process-orientation. Many forms of psychopathology include emotional functioning as primary or secondary features of the clinical syndrome (American Psychiatric Association, 2013) and consider emotional regulation (a MSCEIT component) as primary in the etiology and treatment of the disorder (Gross, 2014). Understanding specific emotional ability deficits and examining emotional processes can enhance counseling psychologists' understanding of clinical disorders and interventions more so than identification of traits. Emotional processes are central to dynamic therapy (Plutchik, 2000) and measures of ego functioning and adaptive defense mechanisms are correlated with EI abilities (Pellitteri, 2002; 2010). The cognitive-emotional processes of the abilities-based model would be congruent with cognitive behavioral therapy (Beck, 2011) and emotion-focused therapy (Greenberg, 2011) that focus on the same intrapersonal dynamics.

Educational settings can also benefit from the process-oriented focus of the abilities-based model, although trait EI has been examined in relation to academic achievement (Perera \& DiaGiacomo, 2013). Psychological consultants, school counselors, and other educators employing psychoeducational curricula and social skills training can readily integrate the EI abilities model that stands alongside of the development of academic abilities. Pellitteri, Stern, Shelton, and Ackerman (2006) present formal and informal methods of embedding abilities-based EI into school program curriculum and the school environment. Formal school-based social-emotional learning programs are typically designed around ability/skill development, have increased in number, and are becoming more readily adopted (Collaborative for Academic, Social and Emotional Learning, 2015; Elias \& Bruene-Butler, 1999; Topping, Holmes, \& Bremmer, 2000; Zins, Weissberg, Wang, \& Walberg, 2004). One program in particular that promotes school-wide program implementation-the RULER approach to emotional literacy in schools (Brackett \& Kremenitzer, 2011; Brackett et al., 2012)—is built explicitly upon the Mayer and Salovey abilities model.

\section{Limitations and Future Research}

The current study examined a college population in a comparison of the two EI measures. This must be considered in any application of these results toward other age groups and populations. EI measurement tools for adolescents and children are relatively new and are extensions of the adult tests with the same formats. Therefore the conclusions of the trait versus ability argument would likely apply in general to younger and older age groups. Comparative studies of the MSCEIT and EQi to date have examined psychometric properties and predictive validity (Livingstone \& Day, 2005; O’Conner \& Little, 2003). A comparison of the MSCEIT and the EQi in clinical populations has not been conducted, but could be a topic for future research.

\section{Conclusions}

The popularity in the lay public and misguided enthusiasm for EI (Antonakis, Ashkanasy, \& Dasborough, 2009; Mayer et al., 2000a; Matthews et al., 2004) must be balanced by careful consideration of the scientific literature and clarity of the diverse models when promoting or applying EI. The findings of the current study indicate that the MSCEIT and EQi are distinct measures that represent very different EI conceptualizations. The 
major implication is that counseling psychologists and other professionals who use instruments labeled "emotional intelligence" must not assume that EI is one unified construct. The types of data generated by the respective measures and underlying implicit assumptions of traits versus abilities must be carefully considered in clinical applications. One must decide which EI model (abilities-based or trait-based) is best suited for assessment and clinical goals, and ensure that it matches the intended purposes and orientations in career, mental health, and educational counseling settings.

\section{References}

Alegre, A. (2012). The relation between the time mothers and children spent together and the children's trait emotional intelligence. Child \& Youth Care Forum, 41(5), 493-508. doi:10.1007/s10566-012-9180-z

American Psychiatric Association. (2013). Diagnostic and statistical manual of mental disorders (5th ed.). Washington, D.C.: Author.

Aminabadi, N. A., Pourkazemi, M., Babapour, J., \& Oskouei, S. (2012). The impact of maternal emotional intelligence and parenting style on child anxiety and behavior in the dental setting. Medicina Oral Patologia Oral y Cirugia Bucal, 17(6), E1089-E1095. doi:10.4317/medoral.17839

Antonakis, J., Ashkanasy, N. M., \& Dasborough, M. (2009). Does leadership need emotional intelligence? Leadership Quarterly, 20(2), 247-261.doi:10.1016/j.leaqua.2009.01.006

Bar-On, R. (1996, August). The era of the EQ: Defining and assessing emotional intelligence. Paper presented at the Annual Convention of the American Psychological Association, Toronto, Canada.

Bar-On, R. (1997). Emotional Quotient Inventory user's manual. Toronto, Canada: Multi-Health Systems Inc..

Bar-On, R. (2000). Emotional and social intelligence: Insights from the Emotional Quotient Inventory. In R. Bar-On, \& J. Parker (Eds.), The handbook of emotional intelligence (pp. 363-388). San Francisco, C.A.: Jossey-Bass.

Beck, J. S. (2011). Cognitive behavior therapy: Basics and beyond (2nd ed.). New York, N.Y.: Guilford Press.

Boring, E. G. (1923, June 6). Intelligence as the tests test it. New Republic, 35, 35-37.

Brackett, M. A., \& Kremenitzer, J. P. (Eds.). (2011). Creating emotionally literate classrooms: An introduction to the RULER Approach to Social and Emotional Learning. Portchester, N.Y.: National Professional Resources.

Brackett, M. A., Rivers, S. E., Reyes, M. R., \& Salovey, P. (2012). Enhancing academic performance and social and emotional competence with the RULER feeling words curriculum. Learning and Individual Differences, 22(2), 218-224. doi:doi:10.1016/j.lindif.2010.10.002

Brophy, J. (2010). Motivating students to learn (3rd ed.). New York, N.Y.: Routledge.

Collaborative for Academic, Social and Emotional Learning (CASEL). (2015). What is social and emotional learning? Retrieved from http://www.casel.org/social-and-emotional-learning/

Cherniss, C. (2000). Social and emotional competence in the workplace. In R. Bar-On, \& J. Parker (Eds.), The handbook of emotional intelligence (pp. 433-458). San Francisco, C.A.: Jossey-Bass.

Davies, M., Stankov, L., \& Roberts, R. (1998). Emotional intelligence: In search of an elusive construct. Journal of Personality and Social Psychology, 75, 989-1015. doi:10.1037/0022-3514.75.4.989

De Clercq, D., Bouckenooghe, D., Raja, U., \& Matsyborska, G. (2014). Unpacking the goal congruence-organizational deviance relationship: The roles of work engagement and emotional intelligence. Journal of Business Ethics, 124(4), 695-711. doi:10.1007/s10551-013-1902-0

Elias, M., \& Bruene-Butler, L. (1999). Social decision-making and problem solving: Essential skills for interpersonal and academic success. In J. Cohen (Ed.), Educating minds and hearts: Social emotional learning and the passage into adolescence. New York, N.Y.: Teachers College Press.

Elias, M., Tobias, S., \& Friedlander, B. (1999). Emotionally intelligent parenting. New York, N.Y.: Harmony Books.

Gardner, H. (1983). Frames of mind: The theory of multiple intelligence. New York, N.Y.: Harper Collins.

Gelso, C.J., Nutt-Williams, E., \& Fretz, B.(2014).Counseling Psychology (3rd ed.). Washington, D.C.: American Psychological Association.

Goleman, D. (1998). Working with emotional intelligence. New York, N.Y.: Bantam.

Graczyk, P., Weissberg, R., Payton, J., Elias, M., Greenberg, M., \& Zins, J. (2000). Criteria for evaluating the quality of school-based social and emotional learning programs. In R. Bar-On, \& J. Parker (Eds.), The handbook of emotional intelligence (pp. 391- 410). San Francisco, C.A.: Jossey-Bass. 
Greenberg, L. S. (2011). Emotion-focused therapy. Washington, D.C.: American Psychological Association.

Greenidge, D., \& Coyne, I. (2014). Job stressors and voluntary work behaviours: Mediating effect of emotion and moderating roles of personality and emotional intelligence. Human Resource Management Journal, 24(4), 479-495. doi:10.1111/1748-8583.12044

Gross, J. (Ed.). (2014). Handbook of emotional regulation. New York, N.Y.: Guildford.

Kaplowitz, M. J., Safran, J. D., \& Muran, C. J. (2011). Impact of therapist emotional intelligence on psychotherapy. Journal of Nervous and Mental Disease, 199(2), 74-84. doi:10.1097/NMD.0b013e3182083efb

Livingstone, H. A., \& Day, A. L. (2005). Comparing the construct and criterion-related validity of ability-based and mixed-model measures of emotional intelligence. Educational and Psychological Measurement, 65(5), 851-873. doi:10.1177/0013164405275663

Magyar-Moe, J. L., Owens, R. L.,\& Conoley, C. W. (2015). Positive psychological interventions in counseling: What every counseling psychologist should know. The Counseling Psychologist, 43(4), 508-557. doi:10.1177/0011000015573776

Magyar-Moe, J. L., Owens, R. L., \& Scheel, M. J. (2015). Applications of positive psychology in counseling psychology: Current status and future directions. The Counseling Psychologist, 43(4), 494-507. doi:10.1177/0011000015581001

Matthews, G., Zeidner, M., \& Roberts, R. D. (2004). Emotional intelligence: Science and myth. Massachusetts: Bradford Books.

Mayer, J. D. (2008). Emotional intelligence: New ability or eclectic traits? American Psychologist, 63(6), 503-517. doi:10.1037/0003-066X.63.6.503.

Mayer, J., Caruso, D., \& Salovey, P. (1999). Emotional intelligence meets traditional standards for an intelligence. Intelligence, 27, 267-298. doi:10.1016/S0160-2896(99)00016-1

Mayer, J., Caruso, D., \& Salovey, P. (2000). Selecting a measure of emotional intelligence: The case for abilities scales. In R. Bar-On, \& J. Parker (Eds.), The handbook of emotional intelligence (pp. 320-342). San Francisco, C.A.: Jossey-Bass.

Mayer, J., \& Salovey, P. (1997). What is emotional intelligence? In P. Salovey, \& D. J. Sluyter (Eds.), Emotional development and emotional intelligence (pp. 3-31). New York, N.Y.: HarperCollins.

Mayer, J., Salovey, P., \& Caruso, D. (1999). Test manual for the MSCEIT research version 1.1 (3rd ed.). Toronto, Canada: Multi-Health Systems.

Mayer, J., Salovey, P., \& Caruso, D. (2000a). Emotional intelligence as zeitgeist, as personality, and as a mental ability. In R. Bar-On, \& J. Parker (Eds.), The handbook of emotional intelligence (pp. 92-117). San Francisco, C.A.: Jossey-Bass.

Mayer, J., Salovey, P., \& Caruso, D. (2000b). Models of emotional intelligence. In R. Sternberg (Ed.), Handbook of intelligence (pp. 396-420). New York, N.Y.: Cambridge University Press.

Multi-Health Systems. (1997). Emotional Quotient Inventory. Toronto, Canada: MHS.

Multi-Health Systems. (1999). Mayer-Salovey-Caruso Emotional Intelligence Test. Toronto, Canada: MHS.

Niles, S. G., \& Harris-Bowlsbey, J. (2009). Career development interventions in the 21st century (3rd ed.). Upper Saddle River, N.J.: Pearson.

Nyklicek, I., Schalken, P., \& Meertens, S. (2014). The role of emotional intelligence in symptom reduction after psychotherapy in a heterogeneous psychiatric sample. Comprehensive Psychiatry, 57, 65-72.doi:10.1016/j.comppsych.2014.11.022

O’Conner, R. M., \& Little, I. S. (2003). Revisiting the predictive validity of emotional intelligence: Self report versus ability based measures. Personality and Individual Differences, 35, 1893-1902.doi:10.1016/S0191-8869(03)00038-2

Owens, R. L., Magyar-Moe, J. L., \& Lopez, S. J. (2015). Finding balance via positive psychological assessment and conceptualization: Recommendations for practice. The Counseling Psychologist, 43(5), 634-670. doi:10.1177/0011000015584956

Parker, J. D. (2000). Emotional intelligence: Clinical and therapeutic implications. In R. Bar-On, \& J. Parker (Eds.), The handbook of emotional intelligence (pp. 490-504). San Francisco, C.A.: Jossey-Bass.

Payton, J. W., Wardlaw, D. M., Graczyk, P. A., Bloodworth, M. R., Tompsett, C. J., \& Weissberg, R. P. (2000). Social and emotional learning: A framework for promoting mental health and reducing risk behaviors in children and youth. Journal of School Health, 70(5), 179-185. doi:10.1111/j.1746-1561.2000.tb06468.x

Pellitteri, J. (2002). The relationship between emotional intelligence and ego defense mechanisms. Journal of Psychology, 136(2), 182-194.doi:10.1080/00223980209604149

Pellitteri, J. S. (2010). Emotional intelligence in the context of adaptive personality: Implications for counselling psychology. Counselling Psychology Quarterly, 23(2), 129-141. doi:10.1080/09515071003775962

Pellitteri, J. S., Stern, R., Shelton, C., \& Ackerman, B. (Eds.). (2006). Emotionally intelligent school counseling. Mahwah, N.J.: Erlbaum. 
Perera, H. N., \& DiaGiacomo, M. (2013). The relationship of trait emotional intelligence with academic performance: A meta-analytic review. Learning and Individual Differences, 28, 20-33.doi:10.1016/j.lindif.2013.08.002

Petrides, K. V. (2011). Ability and trait emotional intelligence. In T. Chamorro-Premuzic, S. von Stumm, \& A. Furnham (Eds.), The Wiley-Blackwell handbook of individual differences (pp. 656-678). West Sussex, United Kingdom: Wiley-Blackwell.

Plutchik, R. (2000). Emotions in the practice of psychotherapy. Washington, D.C.: American Psychological Association.

Rieck, T., \& Callahan, J. L. (2013). Emotional intelligence and psychotherapy outcomes in the training clinic. Training and Education in Professional Psychology, 7(1), 42-52. doi:10.1037/a0031659

Russell, M. T., \& Karol, D. (1994). 16PF fifth edition administrator's manual. Champaign, I.L.: Institute for Personality and Ability Testing, Inc..

Salovey, P., \& Mayer, J. (1990). Emotional intelligence. Imagination, Cognition, and Personality, 9(3), 185-211.

Salovey, P., \& Sluyter, D. (Eds.). (1997). Emotional development and emotional intelligence: Educational implications. New York, N.Y.: HarperCollins.

Schutte, N. S., \& Loi, N. M. (2014). Connections between emotional intelligence and workplace flourishing. Personality and Individual Differences, 66, 134-139.doi:10.1016/j.paid.2014.03.031

Sternberg, R. J. (1990): Metaphors of mind: Conceptions of the nature of intelligence. New York, N.Y.: Cambridge University Press.

Topping, K., Holmes, E. A., \& Bremmer, W. (2000). The effectiveness of school-based programs for the promotion of social competence. In R. Bar-On, \& J. D. Parker (Eds.), The handbook of emotional intelligence (pp. 411-432). San Francisco, C.A.: Jossey-Bass.

Wan, H. C., Downey, L. A., \& Stough, C. (2014). Understanding non-work presenteeism: Relationships between emotional intelligence, boredom, procrastination and job stress. Personality and Individual Differences, 65, 86-90. doi:10.1016/j.paid.2014.01.018

Ybarra, O., Kross, E., \& Sanchez-Burks, J. (2014). The "big idea" that is yet to be: Toward a more motivated, contextual, and dynamic model of emotional intelligence. Academy of Management Perspectives, 28(2), 93-107. doi: 10.5465/amp.2012.0106

Zins, J. E., Weissberg, R. P., Wang, M. C., \& Walberg, H. J. (Eds.). (2004). Building academic success on social and emotional learning: What does the research say? New York, N.Y.: Teachers College Press. 